\title{
A needs assessment study for optimising prescribing practice in secondary care junior doctors: the Antibiotic Prescribing Education among Doctors (APED)
}

Myriam Gharbi ${ }^{1,2^{*}}$ (D, Luke S. P. Moore ${ }^{1,2,3}$, Enrique Castro-Sánchez ${ }^{1,2}$, Elpiniki Spanoudaki ${ }^{2}$, Charlotte Grady ${ }^{2}$, Alison H. Holmes ${ }^{1,2,3}$ and Lydia N. Drumright ${ }^{1,4}$

\begin{abstract}
Background: Appropriate antimicrobial prescribing is essential for patient care, yet up to half of antimicrobial prescriptions written in the UK are sub-optimal. Improving prescriber education has recently been promoted as a mechanism to optimise antimicrobial use, but identification of key learning objectives to facilitate this is so far lacking. Using qualitative methods we investigated junior doctor knowledge, attitudes, and behaviours around antimicrobial prescribing to identify key areas to address in future educational programmes.

Methods: A cross-sectional survey of qualified doctors in training in West London was undertaken exploring antimicrobial prescribing practices and educational needs.

Results: Among 140 junior doctors from 5 London hospitals, a third (34\%) reported prescribing primarily unsupervised, and two thirds (67\%) reported difficulties obtaining prescribing support outside of hours. $20 \%$ stated not feeling confident in writing an antimicrobial prescription, but confidence was increased through having confirmatory diagnostic results (24) and obtaining advice from a senior doctor (26\%); whether this senior was from their own specialty, or an infection-specialist, varied significantly $(p<0.01)$ by experience. Only a small percentage (5-13\%; depending on number of years post-qualification) of participants stated their previous antimicrobial education was effective. $60 \%$ of those in their first year post qualification reported wanting further education in antimicrobial prescribing, rising to $74 \%$ among more experienced junior doctors. Specific areas of educational need identified were (i) principles of antimicrobial prescribing, (ii) diagnosis of infections, (iii) clinical review of patients with infections, (iv) prescribing in the context of antimicrobial resistance, and (v) laboratory testing and test results.

Conclusions: A significant proportion of junior doctors report lone prescribing of antimicrobials in the context of low self-perceived confidence and knowledge in this field, and frequent difficulty in accessing help when necessary. Innovative training, targeting five specific areas identified through this needs assessment, is urgently needed by junior doctors practising in secondary care.
\end{abstract}

Keywords: Antimicrobials, Continuing medical education, Clinical education, Knowledge, Behaviour

\footnotetext{
* Correspondence: m.gharbi@yahoo.fr

${ }^{1} \mathrm{NIHR}$ Health Protection Research Unit in Healthcare Associated Infections

and Antimicrobial Resistance at Imperial College London, Hammersmith

Campus, Du Cane Road, London W12 OHS, UK

${ }^{2}$ National Centre for Infection Prevention and Management, Hammersmith

Campus, Du Cane Road, London W12 OHS, UK

Full list of author information is available at the end of the article
} 


\section{Background}

Appropriate antimicrobial prescribing is essential for optimal clinical care, patient safety, mitigation of antimicrobial resistance (AMR) [1], and reduction of healthcare associated infections [2]. However, up to $50 \%$ of antimicrobial usage is reported to be suboptimal in acute care settings [3]. Improving healthcare professionals' education has recently been widely promoted as a method for potentially encouraging more appropriate use of antimicrobials and improving clinical practice [4-6]. Such education is an essential component of antimicrobial stewardship programmes [7] and a national self-assessment toolkit for organisations, designed to assess their antimicrobial stewardship programmes, recognises education and training of prescribers as an integral component of the organisational approach [8]. Similarly, a recent consensus on reducing medication errors recommended provision of sufficient training of medical students and newly qualified doctors to ensure safer prescribing $[9,10]$.

Although it is recognised that knowledge and experience are required to optimally prescribe antimicrobials, prescribing decisions are often left to junior doctors $[11,12]$. These newly qualified clinicians are a large prescribing group and the most mobile workforce within the National Health Service (NHS) in the United Kingdom (UK), as bi- or tri-annual rotations often result in movement between hospital groups (i.e. Trusts). However, junior doctors, particularly those just starting to practice, may not have the expertise, knowledge or confidence to optimally prescribe antimicrobials, and seniors may not always have the opportunity to review prescriptions written by the juniors working with them [13]. Although junior doctors admit that antimicrobial prescribing is a challenging and complex task, especially for those who are at the beginning of their training [14], they tend to underestimate their own responsibility for preventing AMR [15-17].

Whilst previous exploratory studies have looked at the issues around antimicrobial prescribing mainly for medical students (who are not yet prescribers), including in the United States [18], Europe [19-21] and Democratic Republic of the Congo [22], many of these issues are context specific. UK junior doctors' needs and understanding in AMR and antimicrobial stewardship must be explored if interventions to improve prescribing are to be effective. As not all educational methods are appropriate or successful for adult learners, it is also important to involve junior doctors as co-designers of future educational strategies [14].

This study aims to identify current self-perceived gaps in junior doctors' knowledge, and to understand their perceptions, regarding antimicrobial prescribing. Obtaining a clear picture of this will enable (i) targeted educational programmes to be developed for junior doctor continuing professional development, (ii) inform revision of post-graduate curricula in the area of antimicrobial prescribing and stewardship, and (ii) set a benchmark against which the efficacy of interventions such as these can be assessed.

\section{Methods \\ Design and setting}

A cross-sectional survey of junior doctors in postgraduate training posts in a multicentre teaching hospital network in London, UK, was undertaken in April 2014. The hospital network comprises five hospitals on four sites providing approximately 1500 inpatient beds and nine satellite clinics. To support appropriate antimicrobial prescribing, there is an active antimicrobial stewardship program in place for all hospitals in the network delivered through a multidisciplinary integrated team, i.e. pharmacists, infection control practitioners, and microbiology/ infectious disease physicians.

\section{Participants and recruitment}

All junior doctors (i.e. post-qualification from medical school yet who are still in post-graduate specialty training) at the host hospital network were invited to take part in the study. This included the first 2 years postqualification (in the UK Foundation Year (FY) 1 and FY2 otherwise known as internship) and three to eight years post-qualification (in the UK core trainees (CT), specialty trainees (ST), and specialist registrars (SpRs), otherwise known as residency). The first 2 years of training involve a general approach of learning the broad spectrum of the medical and surgical curriculum, whereas the $3^{\text {nd }}$ year and plus will have an additional specialty to learn in depth.

Recruitment involved both active participant invitations at 16 post graduate teaching sessions in three different hospitals and dissemination of an electronic survey to all junior doctors in post in April 2014 via their hospital network email accounts. The decision to use both methods was made prior to the start of the study. The post graduate teaching sessions are weekly mandatory teaching sessions for all junior doctors, who are expected to attend $70 \%$ of these sessions over an academic year. They cover the abridged post graduate curriculum, without being infection specific, and are part of the continuous professional development for doctors. Direct recruitment at junior doctor training events continued until saturation was reached, as defined by $85 \%$ or more of doctors in training in a session reporting that they had completed the survey already. In order to enhance participation from more senior grade junior doctors, the questionnaire was circulated by an embedded link in an invitation email. A reminder email was sent to all the participants at 2 weeks. A tracking number was 
generated for each participant to ensure confidentiality. All participants were eligible to enter in a prize draw for one of twenty-five $£ 25$ (\$37USD) gift vouchers.

\section{Data collection}

Participants were invited to complete a 45 -item questionnaire on antimicrobial prescribing practices, previous education including medical degree and post-degree training, learning interests, and demographics, that lasted approximately $10 \mathrm{~min}$. The questionnaire had been piloted by 6 healthcare professionals, including 3 infectious disease doctors, in order to assess the clarity and the length of the questions. The questions were constructed following a comprehensive literature review. With respect to antibiotics, participants were asked about prescribing practice; desire for additional training; confidence in prescribing; attitudes toward prescribing policies, healthcare associated infections and AMR; knowledge of prescribing policy and AMR; influences on prescribing practice; sources of information used for prescribing; as well as desirable topics to receive training on and the type and format for such training. All questionnaires were completed anonymously to increase reporting of sensitive information.

The electronic questionnaire was identical to the paper-based one, but delivered via Adobe ${ }^{\bullet}$ FormsCentral. A protocol for data entry was developed and training was provided to ensure consistency between researchers. Information derived from paper-based questionnaires was double-entered into a Microsoft ${ }^{\bullet}$ Access database for accuracy and all inconsistencies were investigated and resolved. Information derived from Adobe Forms was automatically exported to Microsoft Excel.

\section{Data analysis}

Associations between demographics, training interests and attitudes and knowledge to antibiotic prescribing were explored, as was confidence in prescribing and demographics, education history, and year in training by cross tabulations, tests of central tendency and stepwise multivariate logistic regression using a backward elimination approach. All the variables of interest were entered in the multivariate analysis. The reported $\mathrm{p}$-values were considered as two-tailed, and a p-value $<0.05$ was considered to be significant. Statistical analysis was performed using STATA version 12 (STATA Corp, College Station, TX).

\section{Results}

Among 130 junior doctors actively approached during teaching sessions, 109 (response rate 84\%) completed the paper-based questionnaire. These sessions were mainly attended by $1^{\text {st }}$ and $2^{\text {nd }}$ year post-qualified doctors. The survey was sent electronically to 759 junior doctors who were registered with North West London region; a total of 31 completed the questionnaire (response rate: $4 \%$ ); however not all of those on the email distribution list would have been posted to the host Trust during the April 2014 period, and therefore have had access to their hospital email. Of the total of 140 respondents, $75(54 \%)$ were female, 109 (80 \%) were under 30 years-old and $103(74 \%)$ were in their $1^{\text {st }}$ or $2^{\text {nd }}$ post-qualification years (Table 1 ).

\section{Prescribing behaviour}

Whilst junior doctors in their first year postqualification rarely $(n=7,13 \%)$ reported prescribing primarily without senior supervision, those with just 1 year more experience reported doing so frequently $(n=$ $18,46 \%)$. Junior doctors also reported feeling increased confidence in prescribing in this $2^{\text {nd }}$ year postqualification $(n=34,92 \%)$ compared to their $1^{\text {st }}(n=36$, $64 \%$ ). However whilst both doctors who were in their $2^{\text {nd }}$ or $\geq 3^{\text {rd }}$ year post-qualification reported feeling increased confidence in antimicrobial prescribing, they were also more likely to report a need for further antimicrobial education (respectively, $n=32,74$ and $n=29,74 \%$ ) than those in their $1^{\text {st }}$ year post-qualification $(n=35,60 \%)$.

Table 1 Characteristics of Junior Doctors enrolled in the study (Health Education North West London, April 2014)

\begin{tabular}{ll}
\hline $\mathrm{N}$ total participants $=140$ & $\mathrm{~N}^{\mathrm{a}}(\%)$ \\
\hline Gender & $63(45.7 \%)$ \\
Male & $75(54.3 \%)$ \\
Female & \\
Age (years) & $57(41.6 \%)$ \\
$22-25$ & $52(38.0 \%)$ \\
$26-29$ & $28(20.4 \%)$ \\
$30+$ & \\
Current post & $58(41.5 \%)$ \\
$1^{\text {st }}$ year post-qualified & $45(32.1 \%)$ \\
$2^{\text {nd }}$ year post-qualified & $37(26.4 \%)$ \\
$\geq 3^{\text {rd }}$ year post-qualified & \\
Country of medical training & $129(94.2 \%)$ \\
UK & $8(5.8 \%)$ \\
Outside of UK & \\
First post-qualified post & $80(58.8 \%)$ \\
Medicine & $54(39.7 \%)$ \\
Surgery & $2(1.5 \%)$ \\
Other & \\
Currently prescribing antimicrobials in their post & $134(95.7 \%)$ \\
Yes & $6(4.3 \%)$ \\
No & \\
\hline
\end{tabular}

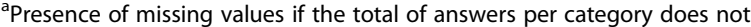
equal 140 
Reported factors influencing confidence in antimicrobial prescribing (Fig. 1) were that a lack of knowledge decreased confidence (36\%), but conversely the presence of knowledge did not necessarily improve confidence. Instead appropriate support (40\%) and diagnosis confirmation (39 \%) were reported as key factors to improving confidence.

When asked about two key antimicrobial prescribing behaviours, that of considering AMR, and that of deescalation of prescriptions, variation was evident between levels of respondent experience. First, appreciation of AMR as a prescription-altering factor was more prevalent among those in their later years of practice $(n=4580, n=2988$, and $n=13 \quad 100 \%$ for $1^{\text {st }}, 2^{\text {nd }}$ and $\geq 3^{\text {rd }}$ year post-qualified, respectively). Second, for prescription de-escalation in line with national policy [23], $1^{\text {st }}$ and $\geq 3^{\text {rd }}$ year post-qualified doctors reported concording with policy guidelines only infrequently (respectively $n=12,22$ and $n=6$, $18 \%$ ), but those in their $2^{\text {nd }}$ year-post-qualification reported observing this guidance in over half of all cases $(n=20,53 \%)$. Only a small proportion of doctors in the three groups believed that non-optimal $(0-23 \%)$, or unsafe (14-35\%), antimicrobial prescriptions are currently reported back to prescribers to enable learning from mistakes (Table 2).

\section{Prescribing support}

Whilst junior doctors in their $2^{\text {nd }}$ year post-qualification indicated that within-specialty seniors were most often their key educators and role models for antimicrobial prescribing ( $n=22,51 \%$ ), among $1^{\text {st }}$ and $\geq 3^{\text {rd }}$ year postqualified respondents infection specialists/microbiologists represented the most frequently cited sources of influence and education (respectively $n=22,39$ and $n=$ 16, $45 \%$ ) (Table 2). Despite this expressed influence from seniors and specialists, and the impact on prescribing confidence provided by appropriate support noted above, around half of the doctors reported difficulty obtaining support on weekends (52) and at night (45\%).

\section{Prescribing education}

Across all respondents, irrespective of their number of years post-qualification, only a small percentage of participants found current teaching sessions to be effective (5-13\%), whilst a large proportion (42-46\%) reported learning better through self-education and reading policies (Table 2). Respondents indicated that they would like additional training to be delivered via ProblemBased Learning (39\%) in the context of series of one hour seminars (39\%) or half day courses (32\%) (Fig. 2). Respondents suggested that the content of the course should mainly cover the following themes: (i) principles

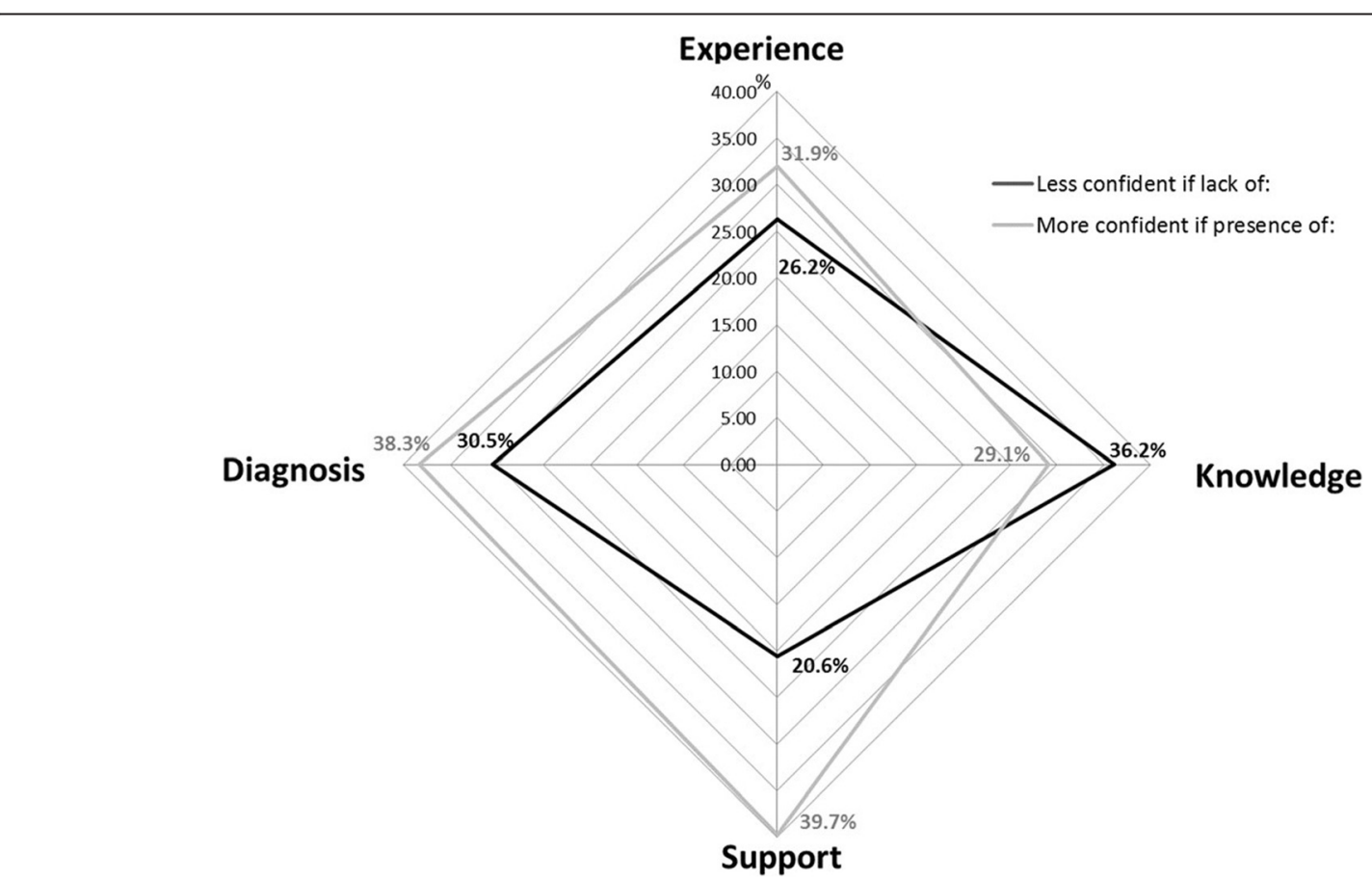

Fig. 1 Factors influencing junior doctor confidence around antimicrobial prescribing $(n=140)$. Legend: This figure represents each of the 4 factors reported as influencing antimicrobial prescribing confidence by junior doctors. These factors form individual axes which have been arranged radially around a point. The value of each aspect is depicted by the node (anchor) on the spoke (axis). A line is drawn connecting the data values for each spoke. Percentages represent the proportions of respondents stating the variable influencing their confidence 
Table 2 Comparison of the prescribing practices, needs and knowledge between post-qualification juniors doctors in London $\left(n=140^{\mathrm{a}}\right.$ )

\begin{tabular}{|c|c|c|c|c|}
\hline & $\begin{array}{l}1^{\text {st }} \text { year post-qualified } \\
\mathrm{n}(\%)(N=58)\end{array}$ & $\begin{array}{l}2^{\text {nd }} \text { year post-qualified } \\
n(\%)(N=45)\end{array}$ & $\begin{array}{l}\geq 3^{\text {rd }} \text { year post-qualified } \\
\mathrm{n}(\%)(N=37)\end{array}$ & $P$ value ${ }^{b}$ \\
\hline \multicolumn{5}{|l|}{ Prescribing practice } \\
\hline \multicolumn{5}{|c|}{ How often do you prescribe antimicrobials? ${ }^{c}$} \\
\hline$\leq$ once a week & $3(5.4)$ & $8(21.6)$ & $6(16.7)$ & \\
\hline 2-4 times/week & $28(50.0)$ & $14(37.8)$ & $16(44.4)$ & \\
\hline$\geq 1 /$ day & $25(44.6)$ & $15(40.6)$ & $14(38.9)$ & 0.21 \\
\hline \multicolumn{5}{|l|}{ Do you prescribe with a senior doctor? ${ }^{c}$} \\
\hline Primarily without senior supervision & $7(12.5)$ & $18(46.2)$ & $20(57.1)$ & \\
\hline Sometimes with a senior doctor & $23(41.1)$ & $10(25.6)$ & $11(31.4)$ & \\
\hline More often with a senior doctor & $26(46.4)$ & $11(28.2)$ & $4(11.5)$ & $<0.01$ \\
\hline \multicolumn{5}{|c|}{ If a non-optimal antimicrobial prescription is noticed, would it be reported back to the prescriber? } \\
\hline Yes, all the time & 0 & $1(3.0)$ & $6(23.1)$ & \\
\hline sometimes & $18(46.2)$ & $21(63.7)$ & $11(42.3)$ & \\
\hline Rarely & $17(43.6)$ & $10(30.3)$ & $5(19.2)$ & \\
\hline Never & $4(10.2)$ & $1(3.0)$ & $4(15.4)$ & $<0.01$ \\
\hline \multicolumn{5}{|c|}{ If an unsafe antimicrobial prescription is noticed, would it be reported back to the prescriber? } \\
\hline Yes, all the time & $6(14.0)$ & $12(35.3)$ & $5(21.7)$ & \\
\hline sometimes & $24(55.8)$ & $19(55.9)$ & $14(60.9)$ & \\
\hline Rarely & $12(27.9)$ & $3(8.8)$ & $2(8.7)$ & \\
\hline Never & $1(2.3)$ & 0 & $2(8.7)$ & 0.05 \\
\hline \multicolumn{5}{|l|}{ Do you consider AMR when prescribing? } \\
\hline Yes & $45(80.4)$ & $29(87.9)$ & $13(100.0)$ & \\
\hline No & $11(19.6)$ & $4(12.1)$ & 0 & 0.24 \\
\hline \multicolumn{5}{|c|}{ How often do you consider IV to oral switch? } \\
\hline Every $24 \mathrm{~h}$ & $12(21.8)$ & $20(52.6)$ & $6(17.6)$ & \\
\hline$>24 \mathrm{~h}$ & $13(23.6)$ & $2(5.3)$ & $7(20.6)$ & \\
\hline Different case by case & $30(54.6)$ & $16(42.1)$ & $21(61.8)$ & $<0.01$ \\
\hline \multicolumn{5}{|l|}{ Do you find easy to switch IV to oral? ${ }^{c}$} \\
\hline Yes & $9(16.4)$ & $11(29.0)$ & $16(47.1)$ & \\
\hline No & $14(25.4)$ & $7(18.4)$ & $6(17.6)$ & \\
\hline Sometimes & $32(58.2)$ & $20(52.6)$ & $12(35.3)$ & 0.04 \\
\hline \multicolumn{5}{|c|}{ Perception about training on antimicrobial prescribing } \\
\hline \multicolumn{5}{|c|}{ Do you feel confident about antimicrobial prescribing? } \\
\hline No & $20(35.7)$ & $3(8.1)$ & $3(8.1)$ & \\
\hline Yes & $36(64.3)$ & $34(91.9)$ & $34(91.9)$ & $<0.01$ \\
\hline \multicolumn{5}{|c|}{ What is your current most effective training? } \\
\hline Prescribing alone on the job & $4(7.4)$ & $4(9.3)$ & $4(10.2)$ & \\
\hline Prescribing with seniors on the job & $18(33.3)$ & $15(34.9)$ & $6(15.4)$ & \\
\hline Ward rounds & $3(5.6)$ & $4(9.3)$ & $7(18.0)$ & \\
\hline Teaching sessions & $4(7.4)$ & $2(4.6)$ & $5(12.8)$ & \\
\hline Reading policy/ Self-study & $25(46.3)$ & $18(41.9)$ & $17(43.6)$ & 0.34 \\
\hline \multicolumn{5}{|l|}{ From whom did you learn the most? ${ }^{c}$} \\
\hline Doctors in my specialty training & $14(25.00)$ & $22(51.2)$ & $12(33.3)$ & \\
\hline Consultants & 2 (3.6) & $4(9.3)$ & $4(11.1)$ & \\
\hline
\end{tabular}


Table 2 Comparison of the prescribing practices, needs and knowledge between post-qualification juniors doctors in London $\left(n=140^{\mathrm{a}}\right)$ (Continued)

\begin{tabular}{llll}
\hline Infection specialists/ microbiologists & $22(39.3)$ & $13(30.2)$ & $16(44.5)$ \\
Pharmacists & $18(32.1)$ & $4(9.3)$ & $4(11.1)$ \\
Would you like more training in antimicrobial prescribing? & & \\
Yes & $35(60.3)$ & $32(74.4)$ & $29(74.4)$ \\
No & $19(32.8)$ & $9(20.9)$ & $8(20.5)$ \\
I do not know & $4(6.9)$ & $2(4.7)$ & $2(5.1)$ \\
\hline
\end{tabular}

Presence of missing values if the total of answers per category does not equal 140

${ }^{b}$ Statistical significance are by Fisher exact test and Chi2 Test based on $p$ value $<0.05$

${ }^{\complement}$ Variables tested in the multivariate model examining the factors associated with confidence prescribing antimicrobials as a junior doctor

of antimicrobial prescribing (64\%), (ii) diagnosis of infections (31\%), (iii) clinical review of patients with infections (57 \%), (iv) aspects of antimicrobial resistance (37 \% reported wanted teaching on mechanisms of resistance, $31 \%$ on epidemiology), and (v) the role of laboratory testing and test results in prescribing (30 \%) (Fig. 2).

\section{Multiple logistic regression analysis}

Investigating the factors impacting junior doctors confidence in prescribing antimicrobials (Table 3), men were significantly more likely to report being confident than women (Odds Ratio [OR] $=2.52$ (Confidence Interval $[\mathrm{CI}], 1.00-6.55))$ and both age groups 26-29 years-old and $\geq 30$ years-old reported more confidence than the 22-25 years-old group in the univariate analysis (respectively, $\mathrm{OR}=3.17$ [CI, 1.13-8.93] and $\mathrm{OR}=3.03[\mathrm{CI}$, 0.79-11.61]) but not in the multivariate analysis. After adjusting for all potential confounders in the multiple logistic regression model, junior doctors' reported confidence in prescribing antimicrobials was greater among those with more experience, i.e. their number of years in practice $\left(\mathrm{OR}=6.97[\mathrm{CI}, 1.25-38.98]\right.$ for $2^{\text {nd }}$ year postqualified and $\mathrm{OR}=5.43[\mathrm{CI}, 1.01-29.17]$ for $\geq 3^{\text {rd }}$ year post-qualified versus $1^{\text {st }}$ year post-qualified) and the frequency with which they reported currently prescribing antimicrobials $(\mathrm{OR}=9.28$ (CI, 1.32-65.15) when prescribing

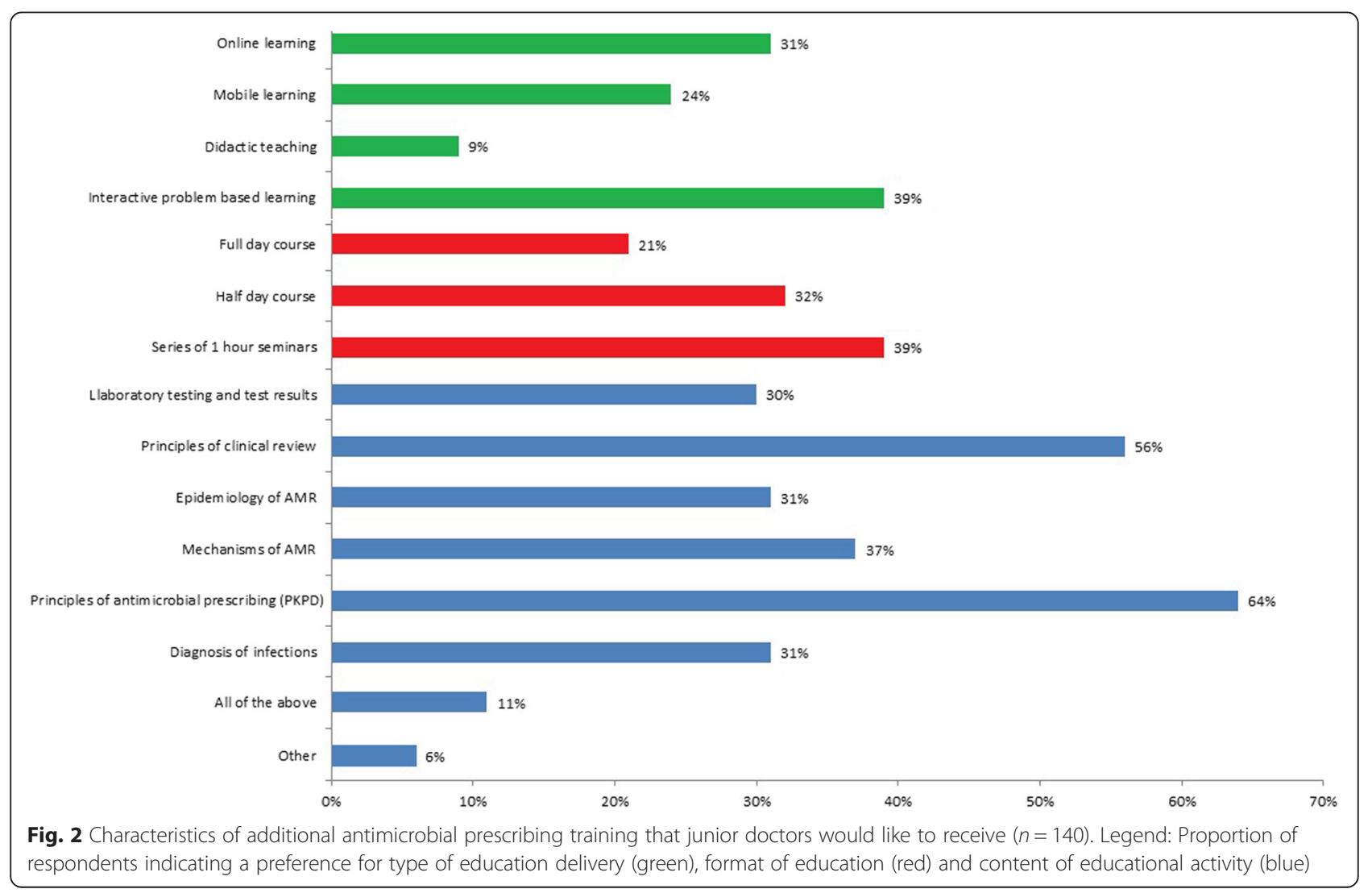


Table 3 Multiple Logistic regression examining associated factors with confidence prescribing antimicrobials as a junior doctor $(n=140)$

\begin{tabular}{|c|c|c|c|c|c|c|}
\hline Associated factors & Unadjusted OR & {$[95 \% \mathrm{Cl}]$} & Crude $p$-value ${ }^{b}$ & Adjusted OR & {$[95 \% \mathrm{Cl}]$} & Adjusted $p$-value ${ }^{b}$ \\
\hline \multicolumn{7}{|l|}{ Gender } \\
\hline Female & $1^{a}$ & & & & & \\
\hline Male & 2.52 & {$[1.00-6.55]$} & 0.05 & & & \\
\hline \multicolumn{7}{|l|}{ Age (year) } \\
\hline $22-25$ & $1^{\mathrm{a}}$ & & & & & \\
\hline $26-29$ & 3.17 & [1.13-8.93] & 0.03 & & & \\
\hline $30+$ & 3.03 & {$[0.79-11.61]$} & 0.11 & & & \\
\hline \multicolumn{7}{|l|}{ Stage of medical training } \\
\hline $1^{\text {st }}$ year post-qualified & $1^{\mathrm{a}}$ & & & $1^{\mathrm{a}}$ & & \\
\hline $2^{\text {nd }}$ year post-qualified & 6.30 & {$[1.71-23.12]$} & $<0.01$ & 6.97 & {$[1.25-38.98]$} & 0.03 \\
\hline$\geq 3^{\text {rd }}$ year post-qualified & 6.30 & {$[1.71-23.12]$} & $<0.01$ & 5.43 & {$[1.01-29.17]$} & 0.05 \\
\hline \multicolumn{7}{|l|}{ Medical degree training } \\
\hline 4 years graduate course & $1^{\mathrm{a}}$ & & & & & \\
\hline 5 years undergraduate entry & 1.91 & {$[0.52-6.99]$} & 0.33 & & & \\
\hline 6 years undergraduate entry & 1.48 & {$[0.36-6.20]$} & 0.59 & & & \\
\hline \multicolumn{7}{|l|}{ Frequency of antimicrobial prescribing } \\
\hline$\leq$ once a week & $1^{\mathrm{a}}$ & & & $1^{\mathrm{a}}$ & & \\
\hline 2-4 times/week & 2.04 & {$[0.59-7.09]$} & 0.26 & 9.28 & {$[1.32-65.15]$} & 0.02 \\
\hline$\geq 1 /$ day & 1.63 & {$[0.47-5.60]$} & 0.44 & 5.24 & [0.87-31.68] & 0.07 \\
\hline \multicolumn{7}{|l|}{ Prescribing alone or not } \\
\hline Mostly with a more senior doctor & $1^{a}$ & & & $1^{\mathrm{a}}$ & & \\
\hline Sometimes with a more senior doctor & 0.76 & {$[0.30-1.94]$} & 0.57 & 0.56 & {$[0.17-1.80]$} & 0.33 \\
\hline Primarily without senior supervision & 15.61 & {$[1.92-127.25]$} & 0.01 & 10.97 & {$[1.02-117.71]$} & 0.05 \\
\hline \multicolumn{7}{|l|}{ To find easy to decide to de-escalate } \\
\hline No & $1^{a}$ & & & $1^{a}$ & & \\
\hline Yes & 8.05 & {$[1.57-41.17]$} & 0.01 & 11.66 & {$[1.59-85.56]$} & 0.02 \\
\hline Sometimes & 1.69 & {$[0.63-4.55]$} & 0.30 & 3.40 & [0.89-12.98] & 0.07 \\
\hline \multicolumn{7}{|c|}{ From whom they learnt the most about antimicrobial prescribing } \\
\hline Doctors in my specialty training & $1^{\mathrm{a}}$ & & & & & \\
\hline Consultants & 1.47 & {$[0.16-13.70]$} & 0.73 & & & \\
\hline Infection specialists/ microbiologists & 0.88 & {$[0.29-2.65]$} & 0.81 & & & \\
\hline Pharmacists & 0.39 & {$[0.12-1.25]$} & 0.11 & & & \\
\hline \multicolumn{7}{|l|}{ Want more training } \\
\hline No & $1^{\mathrm{a}}$ & & & $1^{\mathrm{a}}$ & & \\
\hline Yes & 0.32 & {$[0.09-1.15]$} & 0.08 & 0.15 & {$[0.03-0.69]$} & 0.01 \\
\hline Don't know & 0.16 & {$[0.02-1.00]$} & 0.05 & 0.11 & {$[0.01-1.14]$} & 0.06 \\
\hline
\end{tabular}

${ }^{\text {a Reference }}$

${ }^{\mathrm{b}}$ Statistical significance is based on $\mathrm{p}$ value $<0.05$

2-4 times a week versus less than once a week). Junior doctors who reported prescribing primarily without senior supervision $(\mathrm{OR}=10.97$ [CI, 1.02-117.71] versus those who indicated that they mostly prescribed with a more senior doctor), as well as those who found the switch from intravenous to oral easy $(\mathrm{OR}=11.66(\mathrm{CI}, 1.59-85.56)$ versus those who found it more difficult) reported increased confidence in prescribing. Yet, confidence was lower for those who wanted more training in antimicrobial prescribing $(\mathrm{OR}=0.15$ [CI, 0.03-0.69]).

\section{Discussion}

Our findings showed that a high proportion of junior doctors $(13 \%-57 \%)$ reported prescribing antimicrobials 
without senior supervision, even during their first year of training post-qualification, yet $36 \%$ of respondents self-report low confidence in their ability to complete this task. Respondents cited lack of knowledge as a key reason for this, and going forward the specific topics identified in this study will enable targeted educational programmes and revision of post-graduate curricula to optimise antimicrobial prescribing and stewardship. Yet we also found that increasing knowledge as an isolated variable may not necessarily reciprocally increase confidence; greater support (from seniors and specialists) and more certainty in the diagnosis of infection were stated to drive prescribing confidence. However, junior doctors across the study hospitals noted difficulty in accessing help when necessary, not only during nights and weekends but also a surprising minority during standard working hours (8\%). Whilst it is essential to improve antimicrobial prescribing knowledge, structural and organisational changes must be enacted in parallel, including through decision support tools, and improved diagnostic tests, to enable junior doctors to gain confidence in this field. Similarly, the perception of junior doctors that feedback in cases of sub-optimal, or even unsafe, antimicrobial prescribing is infrequent and unreliable, raises concern. Feedback mechanisms to support quality improvement and patient safety are being developed in healthcare settings addressing a variety of service issues related to this [24, 25]. However, mechanisms to report antimicrobial prescribing issues back to the prescribers are not sufficient and must be enhanced, increasing guideline concordance, improving knowledge, and engendering best practice among junior doctors.

Whilst we found that junior doctors reported coprescribing with a senior less frequently as they progressed in experience, co-prescribing still occurred for $43 \%$ of those who had been qualified for $\geq 3$ years. Furthermore, beyond simply co-prescribing, junior doctors also report numerous sources of support for their prescribing activities. In fact, junior doctors reported that their seniors were one of the most influential actors on their antimicrobial prescribing practice; for those in their second year post-qualification, seniors were more influential even than infection specialists, perhaps because of comparative frequency of contact. This finding correlates with previous work showing the importance of the professional hierarchy and the existence of "prescribing etiquette" as a determinant of antimicrobial prescribing [12]. Therefore, one should consider whether education aimed to optimise antimicrobial prescribing would be most effective among junior doctors, or should perhaps also target seniors. We also acknowledge that further research on more senior level should be conducted. We suggest however, that given we found that a lack of knowledge was associated with low confidence, focussed training (mindful of structural and organisation changes) is likely to increase competence and confidence and enable juniors doctors to challenge existing hierarchies and promote good practice. However, improving knowledge should be supplemented with enhanced decision making skills, as well as communication and negotiation skills in order to impact "prescribing etiquette". In the context of a multi-modal approach to antimicrobial stewardship, the data supports an essential need to improve access to infection specialists, and to put them at the centre of antimicrobial prescribing education.

Given the need for education on antimicrobial prescribing among junior doctors, their perceived needs in terms of content and delivery were also evident from our data. First, up to $20 \%$ of junior doctors, mainly $1^{\text {st }}$ year post-qualification, did not take into consideration AMR when prescribing antimicrobials; such awareness only becomes prevalent in later years, indicating a need for targeted education on the practical implications of AMR early in post-graduate education. Of note, whilst $20 \%$ of prescribers declared that they do not consider AMR when prescribing, there is perhaps cause for optimism given comparator data on appreciation of AMR in prescribing from previous studies $[15,26]$. Second, one of the key antimicrobial stewardship principles - "Start Smart and then Focus" [23] - (which promotes the review of the prescriptions every $24 \mathrm{~h}$ with de-escalation from intravenous to oral when possible), is practiced twice as frequently by the $2^{\text {nd }}$ year post-qualified junior doctors than $1^{\text {st }}$ or $\geq 3^{\text {rd }}$ years. This suggests that key components of antimicrobial stewardship programmes, such as "Start Smart Then Focus" need to be highlighted early in post graduate medical education, but then must be reinforced in later years when more experienced junior doctors have other competing considerations. Third, we found that junior doctors self-reported a need for additional training in the areas of both clinical review of infected patients, and principles of prescribing. This links to established patient safety agendas, and clearly establishes a need for education on sepsis resuscitation [27], and therapeutic drug monitoring [28, 29] respectively.

The identified need for further infection education must be catered for through a learner-centred, mixed method approach and such educational interventions must have a mechanism for evaluating their efficacy. Our data suggests passive educational activities, such as didactic teaching sessions, are not of interest to junior doctors. Rather, interactive approaches such as problem based learning delivered in either one-hour seminars or a half day course are called for, as are learning mechanisms accessible through mobile and on-line platforms; findings compatible with schedules of full-time working professionals, and in line with previous studies [30-33]. 
The findings from this study have several limitations. First, the sample predominantly captured the most junior doctors ( $74 \%$ were $1^{\text {st }}$ or $2^{\text {nd }}$ year post-qualified). We do not know what proportion of prescriptions is made by this group in contrast to those in later years of training. Our results showed that there were no significant differences between the three groups in terms of antimicrobial prescribing frequency. However, further research needs to be conducted on more senior doctors (trainees and consultants) who have limited time for training. Second, our participation rate was excellent for our paper-based survey involving active recruitment during teaching sessions $(84 \%)$ but poor for the electronic version sent via email. This may explain the low participation rate among junior doctors $\geq 3$ years qualified. We may have captured those with more interest in the subject and therefore more knowledge or confidence in prescribing antibiotics. Third, our study has been limited to a London hospital network where the culture of antimicrobial stewardship is reasonably ensconced across the multi-professional healthcare team, possibly influencing responses $[34,35]$. However, the participating junior doctors had received their undergraduate medical education from numerous medical schools across the UK, with fairly standardised curricula in the field of AMR [36], suggesting that our results may be generalisable across the UK, but less likely to other countries where the curriculum on this topic may differ significantly. Lastly, our study described the self-reported perceptions and behaviour of junior doctors' antimicrobial prescribing practice. An observational study objectively assessing knowledge and behaviour around antimicrobial prescribing is clearly indicated.

\section{Conclusion}

This study highlights the need for focused, learnercentred, mixed method approaches to antimicrobial prescribing education among junior doctors. Moreover for the first time specific self-identified learning needs have been identified for this to occur, enabling organisations to create targeted educational programmes and revise post-graduate curricula to optimise antimicrobial prescribing and stewardship. However it also underlines the need for education to be ensconced within an organisational structure providing appropriate infection specialist, decision making, and diagnostic support. To meet these needs, the findings from this study have informed the ongoing development of an educational tool (a Continuing Professional Development accredited short course) which is being validated by junior doctors. This educational tool also uses online and mobile learning that interactively delivers knowledge and will hopefully shape behaviours and attitudes in the areas of (i) principles of antimicrobial prescribing, (ii) diagnosis of infections, (iii) clinical review of patients with infections, (iv) prescribing in the context of antimicrobial resistance, and (v) the role of laboratory testing and test results in prescribing.

\section{Acknowledgements}

We are grateful for the support we received from Susan Farrell, Nisha Shah, Judith Lieber, Liquing Ren in the APED study. We also thank all the junior doctors who responded to our survey. This work was presented in part as an oral communication at the 9th Healthcare Infection Society (HIS)

International Conference, Lyon, 2014 (Abstract ID: 3385) and at the $25^{\text {th }}$ European Congress of Clinical Microbiology and Infectious Diseases, Copenhagen, 2015 (Abstract ID: 2686).

This work was supported by the British Society for Antimicrobial Chemotherapy (BSAC), grant: GA2011-04EDU_V2. The authors acknowledge the UK Clinical Research Collaboration who funds the Centre for Infection Prevention and Management, and the support of the National Institute of Health Research Imperial Biomedical Research Centre (BRC) who funds M.G, L.S.P.M and A.H.H. M.G, L.S.P.M, E.C.S, A.H.H and L.N.D are affiliated with the NIHR Health Protection Research Unit in Healthcare Associated Infection and Antimicrobial Resistance at Imperial College London in partnership with Public Health England (PHE). LND is supported in part by an NIHR Career Development Award (Grant \# NIHR CDF-2011-04-017) and the NIHR funded Cambridge BRC. The views expressed are those of the author(s) and not necessarily those of the NHS, the NIHR, the Department of Health or Public Health England.

\section{Availability of data and materials}

The data supporting our findings will not be shared at this stage. The data have not been entirely exploited yet and further research is currently under consideration. However, the corresponding author should be contacted if any specific request.

\section{Authors' contributions}

MG, LSPM, AHH and LND have conceptualised and designed the study; All the authors have been involved in the collection, acquisition and interpretation of the data; MG analysed the data and drafted the first version of the manuscript and LSPM, ECS, CG, AHH and LND, revised it critically for important intellectual content; the final version was approved to be published by all the authors of the manuscript.

\section{Competing interests}

A.H.H and L.S.P.M have consulted for bioMérieux. All other authors declare no competing interests.

\section{Consent to participate and consent for publication}

Participants were given a verbal and written explanatory introduction of the study and were consented by 'tick box' agreement on both, the paper- and electronic -based questionnaire.

Ethics approval and consent to participate

This study was approved by Imperial College Research Ethics Committee (ICREC reference: ICREC 12 6 _ 7 ).

\section{Author details}

${ }^{1} \mathrm{NIHR}$ Health Protection Research Unit in Healthcare Associated Infections and Antimicrobial Resistance at Imperial College London, Hammersmith Campus, Du Cane Road, London W12 OHS, UK. ${ }^{2}$ National Centre for Infection Prevention and Management, Hammersmith Campus, Du Cane Road, London W12 OHS, UK. ${ }^{3}$ Imperial College Healthcare NHS Trust, Hammersmith Hospital, Du Cane Road, London W12 ONN, UK. ${ }^{4}$ Department of Medicine, University of Cambridge, Cambridge CB2 OQQ, UK.

Received: 25 January 2016 Accepted: 23 August 2016

Published online: 30 August 2016

\section{References}

1. Livermore DM. Minimising antibiotic resistance. Lancet Infect Dis. 2005; 5(7):450-9.

2. Barbut F, Petit JC. Epidemiology of Clostridium difficile-associated infections. Clinical microbiology and infection : the official publication of the European Society of Clinical Microbiology and Infectious Diseases. 2001;7(8):405-10. 
3. Davey P, Brown E, Charani E, Fenelon L, Gould IM, Holmes A, Ramsay CR, Wiffen PJ, Wilcox M. Interventions to improve antibiotic prescribing practices for hospital inpatients. The Cochrane database of systematic reviews. 2013:4:CD003543.

4. Davies SC, Gibbens N. UK Five Year Antimicrobial Resistance Strategy 2013 to 2018. In. London: Department of Health; 2013.

5. WHO. The evolving threat of antimicrobial resistance: Options for action. Geneva: World Health Organisation; 2012.

6. COM. Communication from the commission to the European Parliament and the Council: Action plan against the rising threats from Antimicrobial Resistance. Brussels: European Commission; 2011.

7. Charani $\mathrm{E}, \mathrm{Holmes} \mathrm{AH}$. Antimicrobial stewardship programmes: the need for wider engagement. BMJ quality \& safety. 2013;22(11):885-7.

8. Cooke J, Alexander K, Charani E, Hand K, Hills T, Howard P, Jamieson C, Lawson W, Richardson J, Wade P. Antimicrobial stewardship: an evidence-based, antimicrobial self-assessment toolkit (ASAT) for acute hospitals. J Antimicrob Chemother. 2010;65(12):2669-73.

9. Members of Emerge EMERG, Agrawal A, Aronson JK, Britten N, Ferner RE, de Smet PA, Fialova D, Fitzgerald RJ, Likic R, Maxwell SR, et al. Medication errors: problems and recommendations from a consensus meeting. $\mathrm{Br}$ J Clin Pharmacol. 2009:67(6):592-8.

10. Lewis PJ, Dornan T, Taylor D, Tully MP, Wass V, Ashcroft DM. Prevalence, incidence and nature of prescribing errors in hospital inpatients: a systematic review. Drug safety : an international journal of medical toxicology and drug experience. 2009;32(5):379-89.

11. De Souza V, MacFarlane A, Murphy AW, Hanahoe B, Barber A, Cormican M. A qualitative study of factors influencing antimicrobial prescribing by non-consultant hospital doctors. J Antimicrob Chemother. 2006;58(4):840-3.

12. Charani E, Castro-Sanchez E, Sevdalis N, Kyratsis Y, Drumright L, Shah N, Holmes A. Understanding the determinants of antimicrobial prescribing within hospitals: the role of "prescribing etiquette". Clinical infectious diseases : an official publication of the Infectious Diseases Society of America. 2013;57(2):188-96

13. Charani E, Cooke J, Holmes A. Antibiotic stewardship programmes-what's missing? J Antimicrob Chemother. 2010;65(11):2275-7.

14. Mattick K, Dennis I, Bligh J. Approaches to learning and studying in medical students: validation of a revised inventory and its relation to student characteristics and performance. Med Educ. 2004;38(5):535-43.

15. Pulcini C, Williams F, Molinari N, Davey P, Nathwani D. Junior doctors' knowledge and perceptions of antibiotic resistance and prescribing: a survey in France and Scotland. Clinical microbiology and infection : the official publication of the European Society of Clinical Microbiology and Infectious Diseases. 2011;17(1):80-7.

16. Abera B, Kibret M, Mulu W. Knowledge and beliefs on antimicrobial resistance among physicians and nurses in hospitals in Amhara Region. Ethiopia BMC pharmacology \& toxicology. 2014;15:26.

17. Giblin TB, Sinkowitz-Cochran RL, Harris PL, Jacobs S, Liberatore K, Palfreyman MA, Harrison El, Cardo DM, Team CDCCtPAR. Clinicians' perceptions of the problem of antimicrobial resistance in health care facilities. Arch Intern Med. 2004;164(15):1662-8

18. Abbo LM, Cosgrove SE, Pottinger PS, Pereyra M, Sinkowitz-Cochran R, Srinivasan A, Webb DJ, Hooton TM. Medical students' perceptions and knowledge about antimicrobial stewardship: how are we educating our future prescribers? Clinical infectious diseases : an official publication of the Infectious Diseases Society of America. 2013;57(5):631-8.

19. Pulcini C, Wencker F, Frimodt-Moller N, Kern W, Nathwani D, Rodriguez-Bano J, Simonsen GS, Vlahovic-Palcevski V, Gyssens IC, for the ECWG. European survey on principles of prudent antibiotic prescribing teaching in undergraduate students. Clinical microbiology and infection : the official publication of the European Society of Clinical Microbiology and Infectious Diseases. 2014.

20. Dyar OJ, Pulcini C, Howard P, Nathwani D, Esgap. European medical students: a first multicentre study of knowledge, attitudes and perceptions of antibiotic prescribing and antibiotic resistance. J Antimicrob Chemother 2014;69(3):842-6.

21. Navarro-San Francisco C, Del Toro MD, Cobo J, De Gea-Garcia JH, Vano-Galvan S, Moreno-Ramos F, Rodriguez-Bano J, Pano-Pardo JR Knowledge and perceptions of junior and senior Spanish resident doctors about antibiotic use and resistance: results of a multicenter survey. Enferm Infecc Microbiol Clin. 2013;31(4):199-204.

22. Thriemer K, Katuala Y, Batoko B, Alworonga JP, Devlieger H, Van Geet C, Ngbonda D, Jacobs J. Antibiotic prescribing in DR Congo: a knowledge, attitude and practice survey among medical doctors and students. PLoS One. 2013;8(2):e55495.

23. Ashiru-Oredope D, Sharland M, Charani E, McNulty C, Cooke J, Group AAS. Improving the quality of antibiotic prescribing in the NHS by developing a new antimicrobial stewardship programme: start smart-then focus. J Antimicrob Chemother. 2012;67 Suppl 1:151-63.

24. Thakkar K, Gilchrist M, Dickinson E, Benn J, Franklin BD, Jacklin A, Anti-infective Policy Implementation G. A quality improvement programme to increase compliance with an anti-infective prescribing policy. J Antimicrob Chemother. 2011;66(8):1916-20.

25. Franklin BD, Benn J, Jheeta S, Reynolds M. Shine 2012 final report - Improving patient safety through providing feedback to junior doctors on their prescribing errors: the Prescribing Improvement Model (Imperial College Healthcare NHS Trust). United Kingdom: The Health Foundation; 2014. p. 34.

26. Wester CW, Durairaj L, Evans AT, Schwartz DN, Husain S, Martinez E. Antibiotic resistance: a survey of physician perceptions. Arch Intern Med. 2002;162(19):2210-6.

27. Poeze M, Ramsay G, Gerlach H, Rubulotta F, Levy M. An international sepsis survey: a study of doctors' knowledge and perception about sepsis. Critical care (London, England). 2004;8(6):R409-413.

28. Tobaiqy M, McLay J, Ross S. Foundation year 1 doctors and clinical pharmacology and therapeutics teaching. A retrospective view in light of experience. Br J Clin Pharmacol. 2007;64(3):363-72

29. Newham R, Thomson AH, Semple Y, Dewar S, Steedman T, Bennie M. Barriers to the safe and effective use of intravenous gentamicin and vancomycin in Scottish hospitals, and strategies for quality improvement. Eur J Hosp Pharm. 2015;22(1):32-7.

30. Avorn J, Solomon DH. Cultural and economic factors that (mis) shape antibiotic use: the nonpharmacologic basis of therapeutics. Ann Intern Med. 2000;133(2):128-35.

31. Taylor C, Turnbull C, Sparrow N. Establishing the continuing professional development needs of general practitioners in their first five years after training. Education for primary care : an official publication of the Association of Course Organisers, National Association of GP Tutors, World Organisation of Family Doctors. 2010;21(5):316-9.

32. Pulcini C, Gyssens IC. How to educate prescribers in antimicrobial stewardship practices. Virulence. 2013:4(2):192-202.

33. Ohl CA, Luther VP. Health care provider education as a tool to enhance antibiotic stewardship practices. Infect Dis Clin N Am. 2014;28(2):177-93.

34. Castro-Sánchez E, Charani E, Moore LSP, Gharbi M, Holmes AH. On call: antibiotics"- development and evaluation of a serious antimicrobial prescribing game for hospital care. In: Schouten B, Fedtke S, Schijven M, Vosmeer M, Gekker A, editors. Games for Health 2014: Proceedings of the 4th conference on gaming and playful interaction in healthcare. Wiesbaden, Germany: Springer Vieweg; 2014. p. 1-8.

35. Charani E, Kyratsis $Y$, Lawson W, Wickens H, Brannigan ET, Moore LS, Holmes $\mathrm{AH}$. An analysis of the development and implementation of a smartphone application for the delivery of antimicrobial prescribing policy: lessons learnt. J Antimicrob Chemother. 2013;68(4):960-7.

36. Castro-Sánchez E, Farrell S, Drumright L, Holmes AH. Do we need to review and escalate the antimicrobial stewardship education in health and veterinary undergraduate courses in the United Kingdom? Results of a national survey. Int J Infect Dis. 2014;21:203.

\section{Submit your next manuscript to BioMed Central and we will help you at every step:}

- We accept pre-submission inquiries

- Our selector tool helps you to find the most relevant journal

- We provide round the clock customer support

- Convenient online submission

- Thorough peer review

- Inclusion in PubMed and all major indexing services

- Maximum visibility for your research

Submit your manuscript at www.biomedcentral.com/submit 